\title{
A swelling of the lateral hard palate
}

Jeanne Leduc, DMD

Private practice in Longueuil, QC Canada (this manuscript was written while she was a dental resident at the Faculty of Dental Medicine, Universite Laval, Quebec, QC Canada)

Tran Volong Dao, DMD, FRCD(C), Dipl. ABOMS

Assistant Professor, Department of Stomatology, Faculty of Dental Medicine, Universite de Montreal, Montreal, QC Canada

Adel Kauzman, BDS, DMD, MSc, FRCD(C)

Associate Professor, Department of Stomatology, Faculty of Dental Medicine, Universite de Montreal, Montreal, QC Canada

Gisele N. Mainville, DMD, MSc, FRCD(c), Dipl. ABOMP

Assistant Professor, Department of Stomatology, Faculty of Dental Medicine, Universite de Montreal, Montreal, QC Canada

\section{Corresponding author:}

Gisele N. Mainville, DMD, MSc, FRCD(c), Dipl. ABOMP

Assistant Professor, Department of Stomatology

Oral and Maxillofacial Pathologist

Faculty of Dental Medicine

Universite de Montreal

(514) 343-6111 ext. 37381

gisele.mainville.1@umontreal.ca 


\section{A swelling of the lateral hard palate}

\section{The Challenge}

A 17-year-old male was referred by his general dentist to an oral and maxillofacial surgeon in private practice in Montreal QC for biopsy and further treatment of a painless swelling of the hard palate (Fig. 1). The patient had not noticed the lesion and was unaware of its duration.

The initial review of the medical history did not provide any relevant information and the patient did not report any particular health problems. No significant abnormalities were visible on extraoral examination of the head, neck and visible skin.

The intraoral examination showed a firm swelling on the right side of the hard palate, measuring approximately $20 \mathrm{~mm} \times 30 \mathrm{~mm} \times 10 \mathrm{~mm}$. The overlying mucosa appeared normal. The adjacent teeth were not displaced or mobile. Vitality testing demonstrated that all teeth from the left lateral incisor to the first molar were vital. Radiologic studies, including a panoramic radiograph and CBCT scan, revealed no intrabony lesion or superficial cortical erosion. An incisional biopsy of the mass was performed.

Histopathological evaluation revealed a non-encapsulated proliferation of spindle-shaped cells with wavy nuclei in a dense fibrous stroma. In other regions, the stroma was looser and less collagenized (Fig. 2). The lesional cells at the 
periphery of the tumor blended with adjacent normal tissue. Many mast cells were observed between the spindle cells (Fig. 3 A). Dilated blood vessels and numerous nerve fibres of different calibers were present in the center of the lesion. The lesion was surfaced by unremarkable parakeratinized stratified squamous epithelium. Immunohistochemical studies showed a scattered positive reaction for S-100 protein within the lesional spindle cells (Fig. 3 B).

\section{Differential Diagnosis}

\section{Pleomorphic adenoma}

\section{Mucoepidermoid carcinoma}

\section{Polymorphous low-grade adenocarcinoma}

\section{Non-Hodgkin Lymphoma}

\section{Neurofibroma}

\section{The Diagnosis}

The histopathological examination confirmed the diagnosis of neurofibroma. The S-100 protein immunohistochemical stain mentioned in the diagnostic work-up for this case is a common marker used by pathologists to identify lesions of neural or melanocytic origin. Neurofibromas are benign peripheral nerve sheath tumors that may occur as solitary lesions or multiple lesions associated with a hereditary condition called neurofibromatosis type 1 (NF1, or von 
Recklinghausen's disease of the skin). In the general population, neurofibromas are most commonly cutaneous tumors, but they are not rare in the oral cavity. Intraoral neurofibromas most commonly occur on the tongue and buccal mucosa. They are more frequent in patients with $\mathrm{NF} 1 .^{1-3}$ They arise as a slow-growing, sessile, mobile and usually painless lesion that can vary in size from a small nodule to a large swelling. ${ }^{4}$

Following the diagnosis of a neurofibroma, the possibility of neurofibromatosis must be considered. The patient should be investigated for this condition, especially if they present with additional signs of the disease. The diagnostic criteria for NF1 were established at the National Institutes of Health Development Conference held in 1987, and are presented in Table 1. NF1 is an inherited autosomal dominant disorder affecting about 1 in 3000 individuals. ${ }^{5}$ Although many cases are hereditary, $50 \%$ of patients have no family history and present as spontaneous mutations. ${ }^{6}$

During further clinical evaluation, the patient actually met the diagnostic criteria for NF1. He presented with six or more café au lait macules on his chest, arms and back (Fig. 4 A). He subsequently admitted to having multiple neurofibromas throughout his life. In addition to the palatal neurofibroma, another neurofibroma was actually present on his lower back (Fig. 4 B). He also demonstrated axillary freckling (Fig. 4 C). When questioned on his family history, he revealed that one of his parents was affected by NF1. 
The treatment recommended for neurofibromas of the oral cavity is a complete surgical excision of the lesion, which was performed. Recurrence is rare. There was no recurrence 2 years following treatment.

Malignant transformation is rare in small, solitary neurofibromas. However, for patients with NF1, the lifetime risk of developing a malignant peripheral nerve sheath tumor (MPNST) is $8-13 \% .^{7}$ Most MPNSTs develop in pre-existing plexiform neurofibromas, which, compared to solitary neurofibromas, present as larger, pendulous or diffuse tumors. The prognosis of these malignant tumors associated with NF1 is poor: the five-year survival rate is of $21 \%{ }^{7}$ Compared to the general population, patients with NF1 have a reduced average lifespan by 10-15 years, mostly related to malignant tumors and the development of

hypertension. ${ }^{6,7}$ Systematic, long-term medical follow-up and genetic counseling are important aspects in the management of patients with neurofibromatosis.

\section{Differential Diagnosis}

The clinical differential diagnosis for this swelling of the hard palate included salivary gland tumors (pleomorphic adenoma, mucoepidermoid carcinoma and polymorphous low grade adenocarcinoma) as well as neurofibroma and NonHodgkin lymphoma.

Pleomorphic adenoma. Pleomorphic adenoma, also called benign mixed tumor, is the most common salivary gland neoplasm in both major and minor glands. 
Pleomorphic adenomas are derived from epithelial and myoepithelial elements with a highly variable pattern among different tumors. The palate is the most common site when it occurs in minor glands. The tumor appears as a painless, slowly growing, firm swelling. It can occur at any age, but mostly between the 4th and 7 th decades of life with a female predilection..$^{8-10}$

Mucoepidermoid carcinoma. Mucoepidermoid carcinoma (MEC) is the most common malignant salivary tumor. MEC is composed of mucus-producing cells, epidermoid and intermediate cells. This tumor most commonly arises in the parotid gland, appearing as an asymptomatic slowly growing mass. Intraorally, the palate constitutes the most common site when minor salivary glands are affected. Intraoral MEC also manifests as an asymptomatic swelling, which often has a bluish colour due to its mucus content. MEC can occur from the $2^{\text {nd }}$ to the $7^{\text {th }}$ decades of life. Although this tumor is uncommon in the $1^{\text {st }}$ decade of life, it is the main malignant salivary gland neoplasm in children. ${ }^{10-12}$

Polymorphous low-grade adenocarcinoma. Polymorphous low-grade adenocarcinoma (PLGA) is one of the most common malignancies affecting minor salivary glands. It occurs almost exclusively in minor salivary glands, especially on the hard or soft palate. PLGA usually appears as a painless slowly growing mass. This tumor is characterized by its infiltrating character. It is known to invade the underlying palatal bone and has a tendency to show perineural invasion. Regional metastases to the cervical lymph nodes is relatively infrequent, occurring in up to $17 \%$ of patients. ${ }^{10}$ Distant metastasis is rare. PLGA 
is usually seen in older adults, between the $6^{\text {th }}$ and $8^{\text {th }}$ decades of life, but the tumor may affect patients of all ages. There is a female predilection. ${ }^{10,13,14}$

Non-Hodgkin Lymphoma. Lymphomas are malignant neoplasms of lymphoid tissue. They originate from precursor cells of the B-lymphocyte or T-lymphocyte series. Lymphomas are broadly classified as Hodgkin lymphoma $(\mathrm{HL})$ and nonHodgkin lymphoma. Non-Hodgkin lymphomas (NHL) are by far the most common. Further discussion will be focused on $\mathrm{NHL}$, as intraoral presentation of $\mathrm{HL}$ is quite rare. NHL mostly develop in lymph nodes, but extranodal lymphomas can present in the oral cavity. They can develop in the oral soft tissues or centrally within the jaw bones. Soft tissue lesions appear as boggy and diffuse swellings affecting the posterior hard palate, buccal vestibule, or gingiva. The lesion may be erythematous and sometimes ulcerated. NHL occurs mostly in adults, but children may also be affected. Diffuse large B cell lymphoma is the most frequent $\mathrm{NHL}$ presenting in the oral cavity. ${ }^{15,16}$

\section{Conclusion}

Although neurofibromas are relatively infrequent tumors in the oral cavity, this case shows that it should be included in the differential diagnosis of a palatal mass. A diagnosis of solitary oral neurofibroma should prompt the clinician to further evaluate the patient for NF1, because the oral lesion could be the first manifestation of the systemic condition. In this case, although the patient presented to his dentist with what seemed to be an isolated palatal neurofibroma, 
the final diagnosis was NF1. The collection of signs of the syndrome were not readily apparent and only discovered after careful questioning and clinical examination. Since a small proportion of patients with NF1 will go on to develop MPNSTs or cardiovascular disease with a poor prognosis, early recognition of this condition, genetic counseling and long-term medical monitoring are important. This case demonstrates the important role dentists can play in detecting a previously undiagnosed but significant underlying systemic condition. 


\section{Figures Legends}

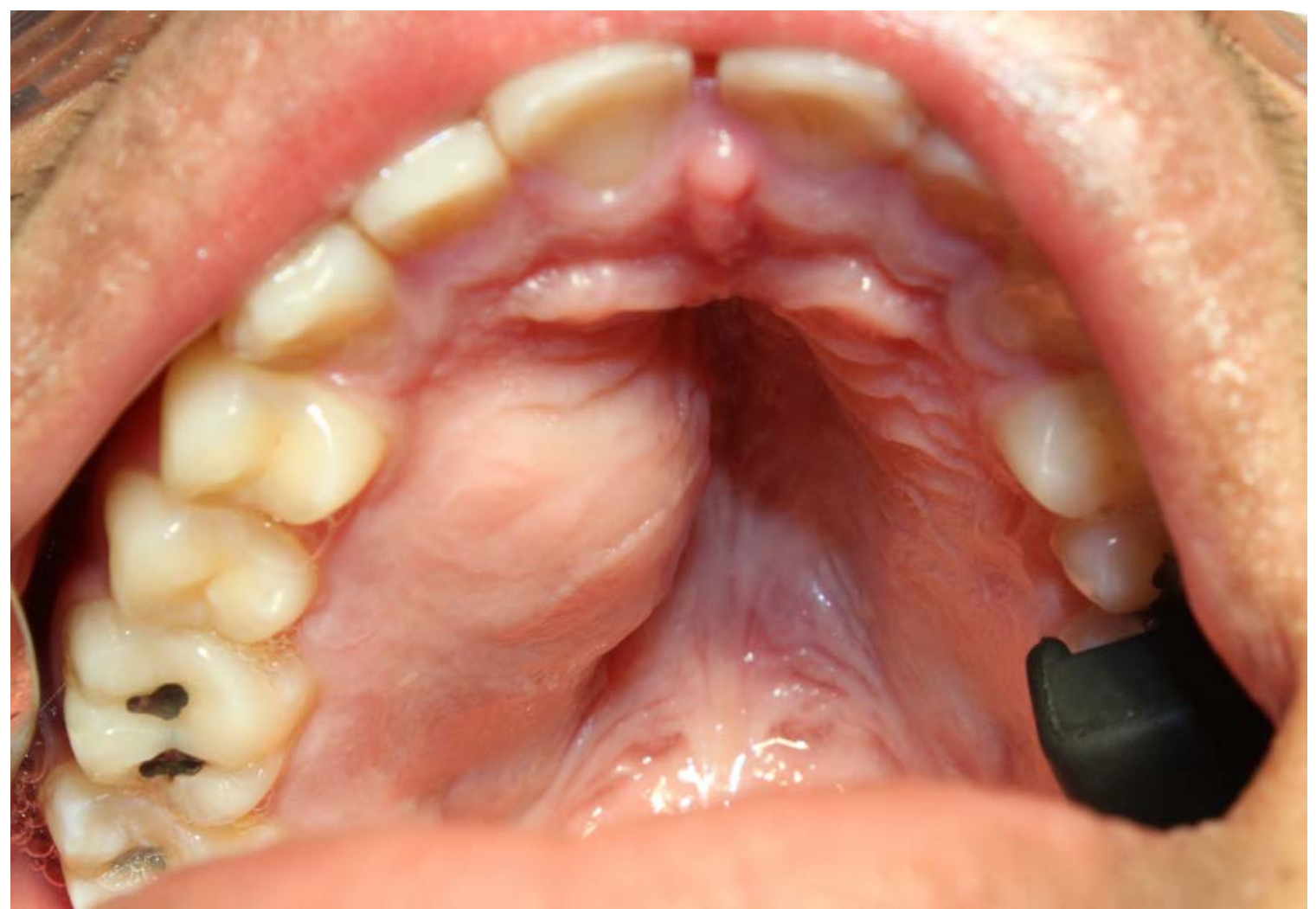

Figure 1. Intraoral view showing the swelling involving the right side of the hard palate. 


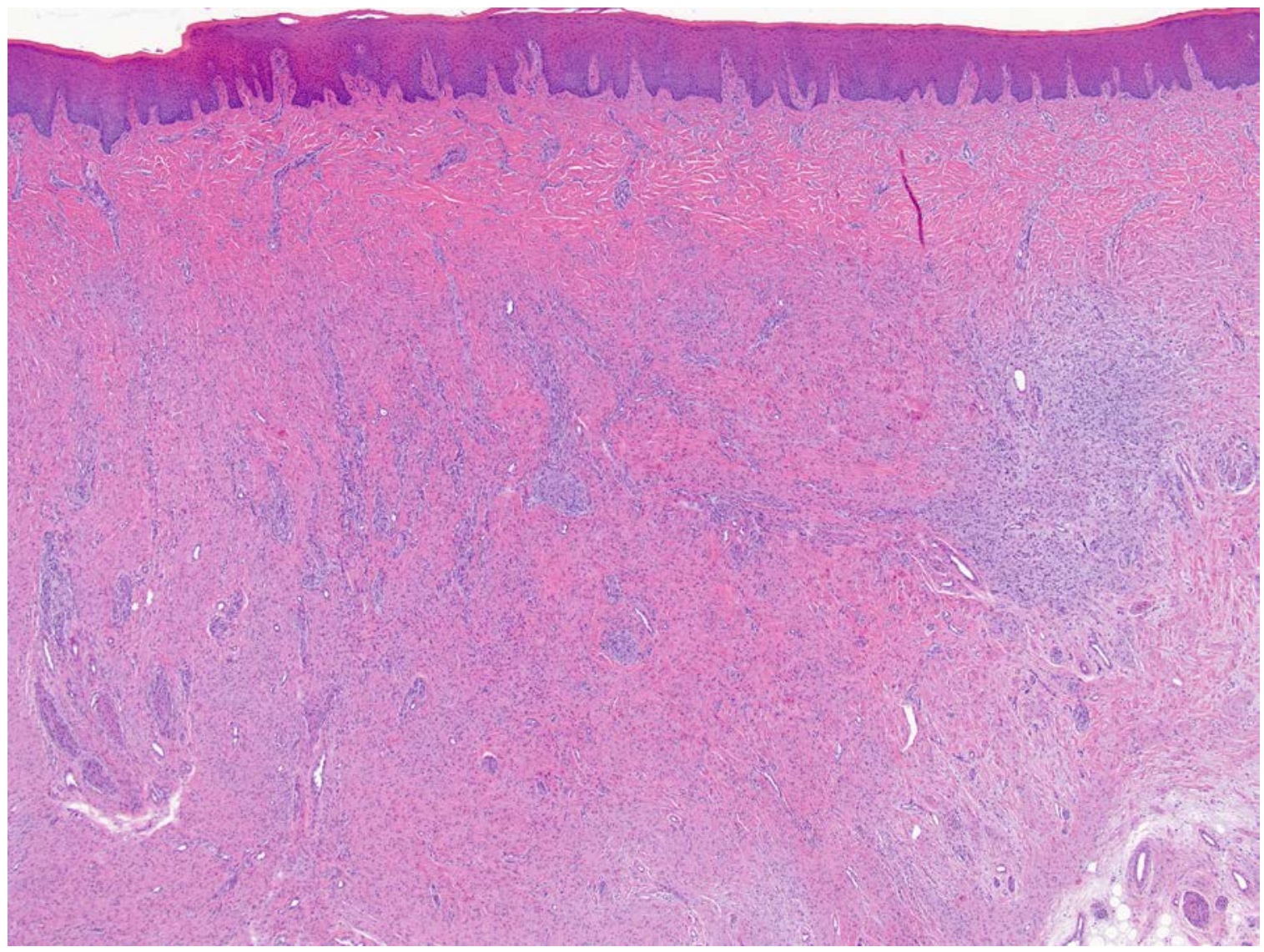

Figure 2. Low-power view showing a non-encapsulated cellular proliferation within the lamina propria. (Original magnification 4x, H\&E).

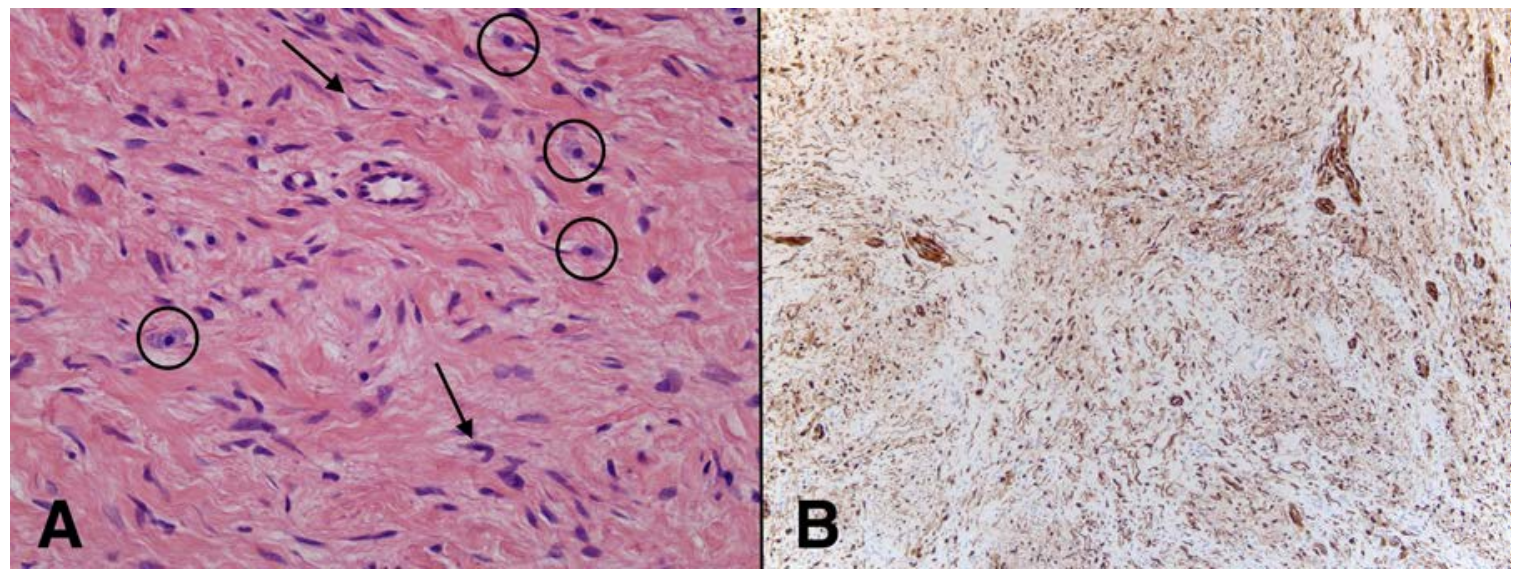

Figure 3. A. High-power view showing spindle-shaped cells with wavy nuclei (arrows) intermingled with multiple mast cells (circles). (Original magnification 
40x, H\&E). B. Medium-power photomicrograph showing scattered S-100 protein immunoreactivity. (Original magnification 10x).
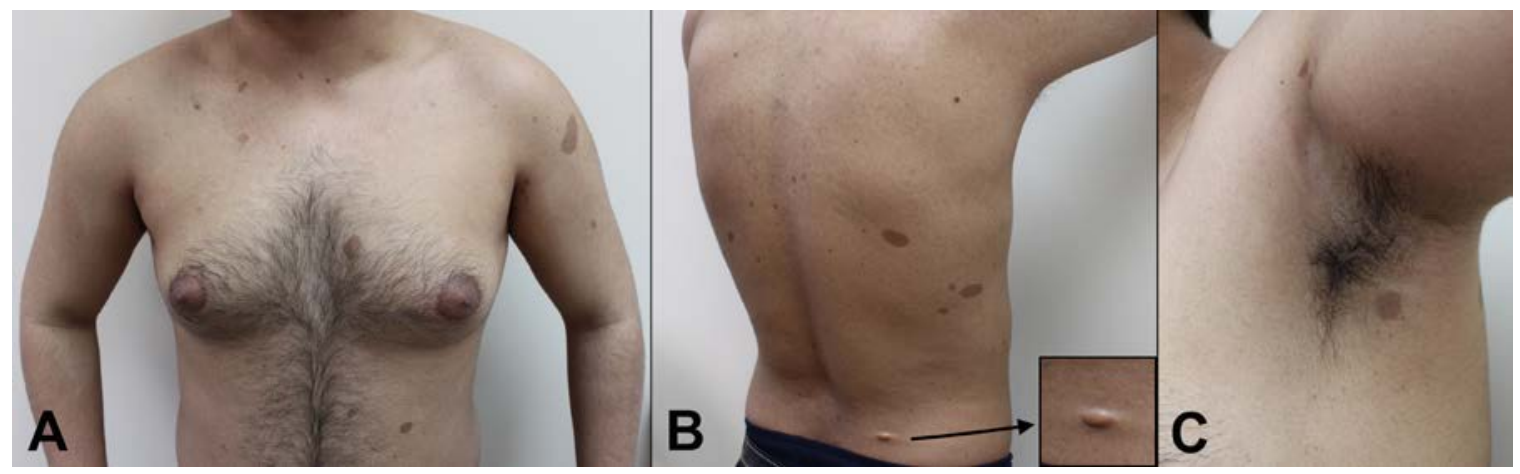

Figure 4. A. Front view showing several café au lait macules on the patient's chest and arms. B. Dorsal view showing other café au lait macules and a neurofibroma on the patient's lower back (magnified inset). C. Axillary freckling.

The diagnostic criteria for NF1 are met if a patient has two or more of the following features:

1. Six or more café au lait macules

- $\quad$ More than $5 \mathrm{~mm}$ in diameter in prepubertal persons

- More than $15 \mathrm{~mm}$ in diameter in postpubertal persons

2. Two or more neurofibromas of any type or one plexiform neurofibroma

3. Freckling in the axillary or inguinal region

4. Optic glioma

5. Two or more Lisch nodules (iris hamartomas)

6. A distinctive osseous lesion (such as sphenoid dysplasia or thinning of long bone cortex, with or without pseudoarthrosis)

7. A first degree relative with NF1 (according to the previously mentioned criteria)

Table 1. National Institutes of Health Diagnostic Criteria for Neurofibromatosis Type 1 (NF1) 


\section{References}

1. Jouhilahti EM, Visnapuu V, Soukka T, et al. Oral soft tissue alterations in patients with neurofibromatosis. Clin Oral Investig 2012;16(2):551-558.

2. Bharath TS, Krishna YR, Nalabolu GR, et al. Neurofibroma of the palate. Case Rep Dent 2014;2014:898505.

3. Shapiro SD, Abramovitch K, Van Dis ML, et al. Neurofibromatosis: oral and radiographic manifestations. Oral Surg Oral Med Oral Pathol 1984;58(4):493-498.

4. Costa FW, Carvalho FS, Sousa CF, et al. Solitary Neurofibroma of the palate. Braz J Otorhinolaryngol 2014;80(2):184-185.

5. Huson SM. The neurofibromatoses: classification, clinical features and genetic counselling. In: Kaufmann D, ed. Neurofibromatoses. Basel: Karger, Basel; 2008 vol 16:1-20.

6. Neville BW, Damm DD, Allen CM, Chi A. Soft tissue tumors. In: Oral and Maxillofacial Pathology. $4^{\text {th }}$ ed. St-Louis: Elsevier; 2016:494-497.

7. Brems H, Beert E, de Ravel T, et al. Mechanisms in the pathogenesis of malignant tumours in neurofibromatosis type 1. Lancet Oncol 2009;10(5):508-515.

8. Wu YC, Wang YP, Cheng SJ, et al. Clinicopathological study of 74 palatal pleomorphic adenomas. J Formos Med Assoc 2016;115(1):25-30.

9. Sharma Y, Maria A, Chhabria A. Pleomorphic adenoma of the palate. Natl J Maxillofac Surg 2011;2(2):169-171. 
10. Neville BW, Damm DD, Allen CM, Chi A. Salivary gland pathology. In: Oral and Maxillofacial Pathology. $4^{\text {th }}$ ed. St-Louis: Elsevier; 2016:444-448, 454-457, 464-465.

11. Jarde SJ, Das S, Narayanswamy SA, et al. Mucoepidermoid carcinoma of the palate: a rare case report. J Indian Soc Periodontol 2016;20(2):203206.

12. Devaraju R, Gantala R, Aitha H, et al. Mucoepidermoid carcinoma. BMJ Case Rep 2014. doi:10.1136/bcr-2013-202776.

13. Elhakim MT, Breinholt $H$, Godballe $\mathrm{C}$, et al. Polymorphous low-grade adenocarcinoma: a Danish national study. Oral Oncol 2016;55:6-10.

14. Kimple AJ, Austin GK, Shah RN, et al. Polymorphous low-grade adenocarcinoma: a case series and determination of recurrence. Laryngoscope 2014;124(12):2714-2719.

15. Reddy I, G S, Reddy Y R, et al. Non-Hodgkin's lymphoma in buccal vestibule -case report. J Clin Diagn Res 2014;8(8):QD01-QD02.

16. Neville BW, Damm DD, Allen CM, Chi A. Hematologic disorders. In: Oral and Maxillofacial Pathology. $4^{\text {th }}$ ed. St-Louis: Elsevier; 2016:553-558. 